\title{
Determining the Predictive Power of Vitamin D Levels in Iron Deficiency Anemia
}

\section{Sorush Niknamian}

PhD in Cell and Molecular Biology, Board Member of Weston A Price Foundation, Washington DC, USA and Active Member of Federal Health Professionals at US Army Forces, United States of America

\begin{abstract}
:
Background:Iron deficiency anemia is one of the most common hypochromic microcytic anemias and nutritional disorders in today's world. Vitamin $D$ is an important steroid hormone for the metabolism of serum calcium and phosphorus and plays a major role in the function of various body systems. Evidence suggests that vitamin $D$ deficiency is associated with iron deficiency anemia. We aimed to compare the serum level of vitamin $D$ between children with iron deficiency anemia and healthy ones. Methods: This case-control study was conducted on 60 patients with iron deficiency anemia and 60 healthy ones who did not suffer from iron deficiency anemia. Patients participated in the study voluntarily. Vitamin D levels were measured using HPLC and ferritin by RIA method. To estimate the predictive value of vitamin D levels in iron deficiency anemia, ROC curve analysis

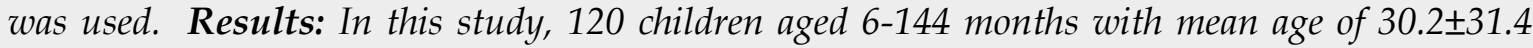
months were analyzed; $49.2 \%$ of them were boys and $50.8 \%$ were girls. Vitamin D levels varied from 4.8 to $63.2 \mathrm{ng} / \mathrm{ml}$ with a mean of $23.87 \pm 12.57 \mathrm{ng} / \mathrm{ml}$ in all patients $(19.25 \pm 9.15 \mathrm{ng} / \mathrm{ml}$ in the case group and $28.48 \pm 13.84 \mathrm{ng} / \mathrm{ml}$ in the control group $(P<0.001)$. In other words, patients with a vitamin D level $<23.6 \mathrm{ng} / \mathrm{ml} \mathrm{should} \mathrm{be} \mathrm{investigated} \mathrm{for} \mathrm{iron} \mathrm{deficiency} \mathrm{anemia,} \mathrm{and} \mathrm{sufficient} \mathrm{vitamin}$ $D$ had a protective effect on iron deficiency anemia and each unit increase in vitamin $D$ decreased the chance of iron deficiency anemia by $7.8 \%$. Conclusion: The prevalence of simultaneous iron deficiency anemia and vitamin $D$ deficiency is very high in children and there is a significant relationship between serum levels of 25(OH)D and hemoglobin.
\end{abstract}

Keywords :

Iron deficiency anemia; vitamin D deficiency; children

\section{Introduction}

Iron deficiency anemia is currently one of the most common nutritional disorders $(1,2)$. This type of anemia is considered the most widespread type of anemia in the world (3). Two billion people have anemia in the world, $50 \%$ of which are iron deficiency $(4,5)$. Iron deficiency with or without anemia is associated with impaired psychological development, and the presence of this substance is very important in the better performance of the nervous system and brain development (2, 4, 6-11).

Vitamin $\mathrm{D}$ is an important steroid hormone for the metabolism of serum calcium and phosphorus and has a major role in the function of muscle nervous system, optimal muscle health, immune system, blood pressure and cancer (12-16). Several studies reported that the incidence of vitamin D deficiency is increasing and nutritional rickettsia in children and adolescents is a global problem, despite nutritional enrichment programs in the United States and other countries (1723).

Various basic and clinical studies indicated the influence of deficiencies of these two micronutrient on each other. For example, patients with iron deficiency anemia seem to have less activities outside the house, due to fatigue and weakness, and are exposed to sunlight less and therefore lack vitamin D (24). Also, iron deficiency impairs the intestinal absorption of fat soluble vitamins, such as vitamin $D$, thus, iron deficiency is a significant factor in reducing serum vitamin $\mathrm{D}$ levels $(3,25)$. Vitamin $\mathrm{D}$ is a very important regulator of the hepcidin-ferroportin axis in the body, and decreased vitamin D levels help increase the expression of hepcidin that reduces plasma 
iron concentrations by inhibition of ferroportin (26-28). It has been shown that patients with vitamin $\mathrm{D}$ deficiency are more likely to have iron deficiency anemia and lower hemoglobin levels $(25,29-31)$. We aimed to compare the serum levels of vitamin $\mathrm{D}$ in children with iron deficiency anemia and the control group to investigate the relationship between iron deficiency anemia and vitamin $\mathrm{D}$ deficiency in children.

\section{Materials and Methods}

This case-control study was performed on children who referred to Shahid Hejazi Hospital in Shiraz, Iran, using the convenient sampling method. The sample size was calculated according to $n=\frac{2\left(t_{\alpha, v}+t_{\beta(1), v}\right)^{2}}{(\partial)^{2}}$ formula, considering error of $5 \%(80 \%$ power and $50 \%$ effect size in the two groups by a ratio of 1 to 1$) .120$ children aged 6 months to 12 years (60 with iron deficiency anemia and 60 healthy ones who did not have iron deficiency anemia) were investigated from November 2016 to end of July 2017.

The inclusion criteria were age between 6 months and 15 years and the exclusion criteria consisted of acute and critical illness, genetic and metabolic disorders, any underlying diseases, and the use of certain drugs (like anticonvulsants). Groups were matched according to age and gender. After obtaining permission from patients and explaining the study objectives to patients, their information, including demographics and other serum values, measured by laboratory tests, were recorded by the researcher on the checklist and the contact number of the patients was recorded for follow up. Patients were excluded from the study, if they did not want to continue the research. The research protocol was approved by the Vice-Chancellor of Research Council Committee of Azad University of Kazerun.

Lab tests included: CBC, ferritin, calcium, phosphorus, and 25(OH)D3. The vitamin D was measured by HPLC and ferritin by RIA method.

The inclusion criteria for patients with iron deficiency anemia was a documented history of poor iron nutrient intake, MCV $<70(\mathrm{Fl})$, ferritin $<15 \mathrm{ng} / \mathrm{ml}$, hemoglobin $<11 \mathrm{~g} / \mathrm{dl}$, and RDW $>16 \%$.

The serum levels of vitamin $\mathrm{D}$ were divided into four categories:

1. Normal: Serum $25(\mathrm{OH}) \mathrm{D}_{3}>30 \mathrm{ng} / \mathrm{ml}$.

2. Insufficient: Serum $25(\mathrm{OH}) \mathrm{D}_{3}$ of $20-30$.

3. Partial deficiency: Serum $25(\mathrm{OH}) \mathrm{D}_{3}$ of $10-20$

4. Severe deficiency: Serum $25(\mathrm{OH}) \mathrm{D}_{3}$ of $<10$

Quantitative data was reported by mean \pm SD and qualitative data by number (\%). T-test and chi-square tests were used to compare the two groups. Also, the ROC curve analysis was used to determine the predictive power of the test. The software used was SPSS version 16. (SPSS for Windows, Version 16.0, Chicago, SPSS Inc.)

\section{Discussion}

In this study, 120 children aged between 6 and 144 months were analyzed with a mean age of $30.2 \pm 31.4$ months; $49.2 \%$ of them were boys and $50.8 \%$ were girls. The serum level of vitamin $\mathrm{D}$ in the whole sample varied from 4.8 to $63.2 \mathrm{ng} / \mathrm{ml}$ with a mean level of $23.87 \pm 12.57 \mathrm{ng} / \mathrm{ml}$ $(19.25 \pm 9.15 \mathrm{ng} / \mathrm{ml}$ in iron deficiency anemia group and $28.48 \pm 13.84$ in the control group (Table 1 and Figure 1). 
Table 1. Mean and distribution of vitamin D levels in the two study groups

\begin{tabular}{|l|l|l|l|l|}
\hline & \multicolumn{3}{|c|}{ Groups } & P-value \\
\cline { 2 - 4 } & Total (N=120) & Case (N=60) & $\begin{array}{l}\text { Control } \\
\text { (N=60) }\end{array}$ & \\
\hline Vitamin D levels & $23.87 \pm 12.57$ & $19.25 \pm 9.15$ & $28.48 \pm 13.84$ & $<0.001$ \\
\hline $\begin{array}{l}\text { Severe } \\
\text { deficiency }\end{array}$ & $14(11.7)$ & $9(15)$ & $5(8.3)$ & 0.002 \\
\cline { 1 - 4 } $\begin{array}{l}\text { Partial } \\
\text { deficiency }\end{array}$ & $40(33.3)$ & $27(45)$ & $13(21.7)$ & \\
\hline Insufficiency & $33(27.5)$ & $16(26.7)$ & $17(28.3)$ & \\
\hline Normal & $33(27.5)$ & $8(13.3)$ & $25(41.7)$ & \\
\hline
\end{tabular}

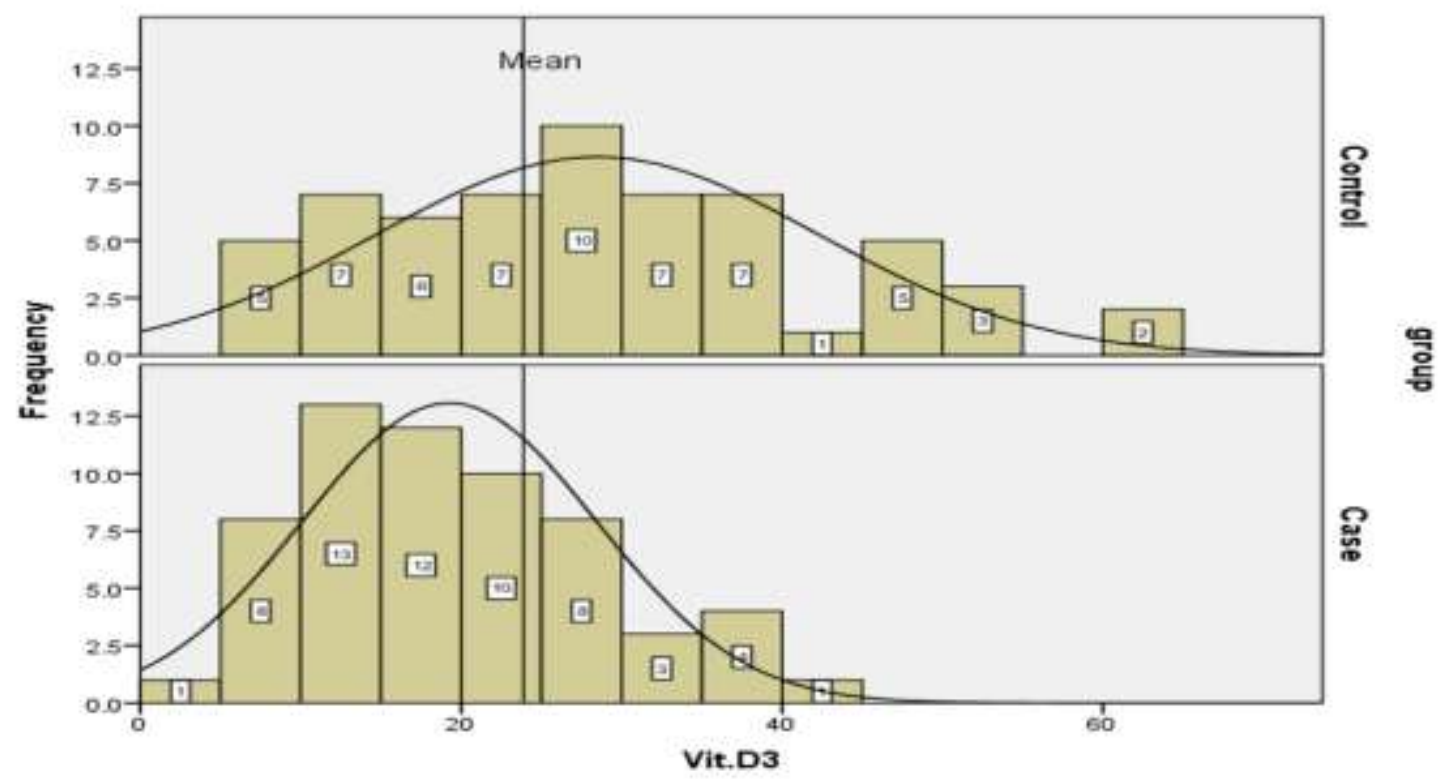

Figure 1. The distribution of vitamin $\mathrm{D}$ levels in two groups. The midline shows total mean. According to this figure, the number of individuals with a higher total mean in the control group was more than the case group.

Based on the classification of different levels of vitamin D in the whole sample, $11.7 \%$ $(\mathrm{N}=14)$ had severe deficiency, 33.3\% $(\mathrm{N}=40)$ had partial deficiency, 27.5\% (N=33) had insufficiency, and $27.5 \%(\mathrm{~N}=33)$ had normal levels of vitamin $\mathrm{D}$ : in the iron deficiency anemia group, $15 \%$ (9 cases) had severe deficiency, 45\% (27 cases) had partial deficiency, $26.7 \%$ (16 cases) had insufficiency, and only $13.3 \%$ (8 cases) had normal serum levels of vitamin $\mathrm{D}$, and in the control group, $8.3 \%(\mathrm{~N}=5)$ had severe deficiency, $21.7 \%(\mathrm{~N}=13)$ had partial deficiency, $28.8 \%$ $(\mathrm{N}=17)$ had insufficiency, and $41.7 \%(\mathrm{~N}=25)$ had normal serum levels of vitamin $\mathrm{D}$ (Table 1).

To estimate the predictive value of vitamin $\mathrm{D}$ levels in iron deficient group, ROC curve analysis was used, the results of which and area under the curve, sensitivity and positive and negative predictive values are summarized in table 2 . Based on this analysis, the best cut-point was determined to be 23.6 (close to the overall mean) (Figure 2). In other words, children with a vitamin $\mathrm{D}$ level of less than $23.6 \mathrm{ng} / \mathrm{ml}$ can be referred to as iron deficiency anemia. The predictive power of this test was $70 \%$ to distinguish the patients and healthy ones. 
Table 2. The statistical indices of predictive power of vitamin $\mathrm{D}$ in diagnosis of iron deficiency

\begin{tabular}{|l|l|l|}
\hline Index & No $(\%)$ & $95 \%$ CI \\
\hline AUC ROC & 70 & $61-78$ \\
\hline Sensitivity & 71.67 & $58.6-82.5$ \\
\hline Specifity & 65 & $51.6-76.9$ \\
\hline Positive predictive value & 67.19 & $58.34-74.96$ \\
\hline Negative predictive value & 69.64 & $59.56-78.13$ \\
\hline
\end{tabular}

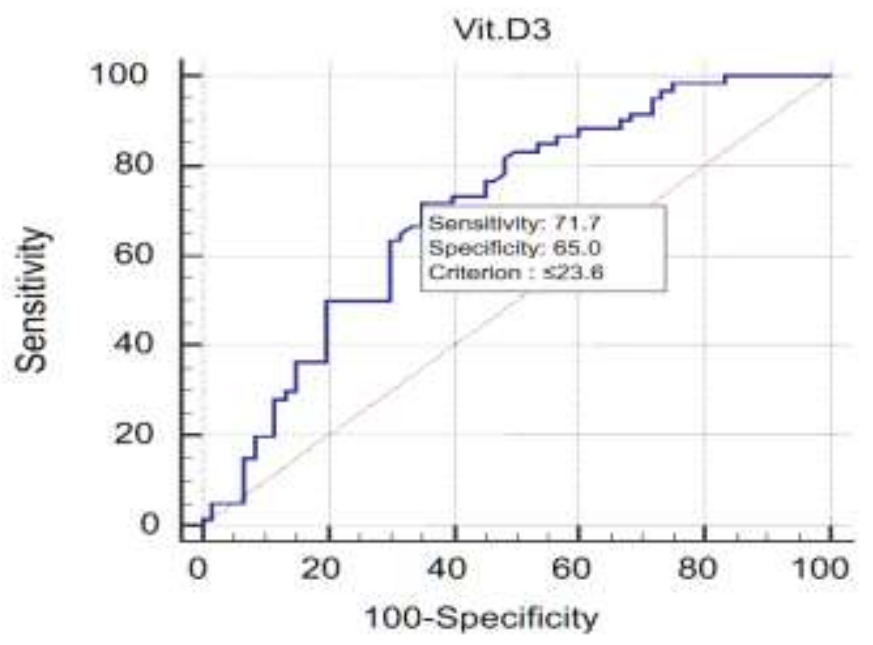

Figure 2. The area under curve (AUC) of ROC represents the predictive power of vitamin D levels in children with iron deficiency. This level is 0.70 and is practically between 0.5 and 1 ; values $>0.5$ and closer to 1 shows higher test's power for distinguishing. In fact, AUC of 0.5 shows complete chance in distinguishing power of the test.

Also, vitamin D level was protective against iron deficiency, as an increase in vitamin D decreases the chance of anemia by $7.8 \%$.

There was a significant relationship between the intake of iron supplementation in childhood and folic acid and iron intake during pregnancy by the mother with iron deficiency anemia in the child and vitamin D deficiency, as children and mothers with full iron supplementation had less chance of iron deficiency anemia than those without $(\mathrm{P}<0.001)$. There was no significant difference between the nutrition types of children (formula or breast milk) with iron deficiency anemia and vitamin $\mathrm{D}$ levels.

There was a significant relationship between educational level and occupation of father with iron deficiency anemia and vitamin D levels and the distribution of educational level and occupation of father were significantly different between the two groups, as subjects in the control group had higher educational level than that in anemia group $(\mathrm{P}<0.001)$. The frequency of labor and free jobs of the fathers in the case group was more than hat in the control group $(\mathrm{P}<0.012)$. Perhaps, iron deficiency anemia occurs more in low-income families. There was no significant difference in the relationship of educational level and occupation of mother with iron deficiency anemia and vitamin $\mathrm{D}$ levels between two groups.

In this study, $86.7 \%$ of patients with iron deficiency anemia had a serum level of vitamin D below normal limits, compared to the control group, $58.3 \%$ of whom had a serum level of vitamin $\mathrm{D}$ below normal limits, which can point out the importance of measuring $25(\mathrm{OH}) \mathrm{D}_{3}$ in children with iron deficiency.

Iron and vitamin $\mathrm{D}$ are two micronutrients necessary for the growth and development of infants and deficiency of these two substances has harmful effects in infants below 24 months of 
age (6). Individuals with iron deficiency anemia have less activities outside the house, due to fatigue and weakness, and are exposed less to sunlight and therefore lack vitamin D (24). Also, iron deficiency impairs the intestinal absorption of fat soluble vitamins, such as vitamin $\mathrm{D}$, thus, iron deficiency is a significant factor in reducing serum levels of vitamin $\mathrm{D}(3,25)$.

Iron deficiency can reduce 1, 25-dihydroxy-cholecalciferol (6). Iron plays a role in the second activation stage of vitamin $\mathrm{D}$ in kidneys, so iron deficiency can reduce the production of active form of vitamin D $(25,32)$. In the study of H.Grindulis and colleagues, there was a significant relationship between iron deficiency anemia and vitamin D deficiency in children and two-fifths of children in their study had anemia, two-fifths vitamin D deficiency, and one-fifth anemia and vitamin D deficiency (30).

In the study by Jin et al. on 102 infants (3 to 24 months), there was a significant association between iron deficiency and breastfeeding $(\mathrm{P}<0.001)$. Also, vitamin $\mathrm{D}$ deficiency in infancy was significantly correlated with vitamin $\mathrm{D}$ deficiency during pregnancy $(\mathrm{P}=0.01)$ (6). However, in our study, child's nutrition (breast milk or formula) had no significant association with iron deficiency anemia or serum levels of vitamin $\mathrm{D}(\mathrm{P}=0.649)$.

In one study it was concluded that children and mothers with a history of anemia before pregnancy had lower levels of ferritin and $25(\mathrm{OH}) \mathrm{D}$. The researchers concluded that it is necessary to monitor not only iron, but also vitamin D levels, in breast fed children whose mothers had anemia before pregnancy (33).

In another study in the United States in 2014, it was concluded that $25(\mathrm{OH}) \mathrm{D}$ deficiency was associated with an increased risk of anemia in healthy children in the United States, but the threshold level of $25(\mathrm{OH}) \mathrm{D}$ for low hemoglobin in black children were lower, compared to white children (27).

Other researchers found that anemia decreased in Mexican children by a generalized rich diet (especially in vulnerable people), and Vitamin D deficiency has also improved (34). Another study showed that vitamin D deficiency is associated with iron deficiency anemia in Korean children. In the initial care by physicians, the possibility of vitamin $\mathrm{D}$ deficiency with iron deficiency anemia should be considered and vitamin D supplements should be prescribed in addition to iron supplements (24).

In our study, assessing iron deficiency anemia using serum level of vitamin D by ROC curve indicated 23.6 as the best cut-point (close to the overall mean), namely, children with a vitamin $\mathrm{D}$ level of $<23.6 \mathrm{ng} / \mathrm{ml}$ are $70 \%$ likely to have iron deficiency anemia and sufficient vitamin $\mathrm{D}$ was protective against iron deficiency, as each unit increase in vitamin $\mathrm{D}$ decreased the chance of iron deficiency anemia by $7.8 \%$.

Vitamin D receptors exist in all precursor RBCs in bone marrow (35) and insufficient level of $25(\mathrm{OH}) \mathrm{D}$ leads to a decrease in the production of calcitrol in bone marrow and decreases hematogenesis function (27). Vitamin D deficiency affects the incidence of iron deficiency anemia $(25,29,31)$, as in children with vitamin D deficiency, hemoglobin and iron levels were significantly lower than children with normal levels of vitamin D $(3,30)$. Shikha Sharma and colleagues reported that physicians should assess vitamin D levels in children with anemia and prescribe adequate supplementation to prevent deficiency of both (3).

\section{Conclusion}

The findings of this study showed a high prevalence of vitamin $\mathrm{D}$ deficiency in children with iron deficiency anemia and a significant relationship between serum levels of $25(\mathrm{OH}) \mathrm{D}$ and hemoglobin levels. Given the high prevalence of vitamin D deficiency in patients with iron deficiency anemia, physicians should check the serum levels of vitamin $\mathrm{D}$, in addition to ferritin, in children with anemia and treat both, if necessary. 


\section{References}

Abdul-Razzak KK, Khoursheed AM, Altawalbeh SM, Obeidat BA, Ajlony MJ. Hb level in relation to vitamin D status in healthy infants and toddlers.Public health nutrition. 2012;15(9):16831687.

Al-Zabedi EM, Kaid FA, Sady H, Al-Adhroey AH, Amran AA, Al-Maktari MT. Prevalence and risk factors of iron deficiency anemia among children in Yemen. American journal of health research. 2014; 2(5):319-326.

Atkinson MA, Melamed ML, Kumar J, Roy CN, Miller ER, 3rd, Furth SL, et al. Vitamin D, race, and risk for anemia in children. J Pediatr. 2014;164(1):153-158 e151.

Bener A, Kamal M, Bener H, Bhugra D. Higher prevalence of iron deficiency as strong predictor of attention deficit hyperactivity disorder in children. Annals of medical and health sciences research. 2014; 4 (Suppl 3):S291-S297.

Beucher G, Grossetti E, Simonet T, Leporrier M, Dreyfus M. Iron deficiency anemia and pregnancy. Prevention and treatment. J Gynecol Obstet Biol Reprod (Paris). 2011; 40(3): 185-200.

Blanco-Rojo R, Perez-Granados AM, Toxqui L, Zazo P, de la Piedra C, Vaquero MP. Relationship between vitamin $\mathrm{D}$ deficiency, bone remodeling and iron status in iron-deficient young women consuming an iron fortified food. European journal of nutrition. 2013; 52(2):695-703.

Bischoff-Ferrari HA, Giovannucci E, Willett WC, Dietrich T, Dawson-Hughes B. Estimation of optimal serum concentrations of 25 -hydroxyvitamin D for multiple health outcomes. Am J ClinNutr 2006; 84:18-28.

Bacchetta J, Zaritsky JJ, Sea JL, Chun RF, Lisse TS, Zavala K, et al. Suppression of iron-regulatory hepcidin by vitamin D. Journal of the American Society of Nephrology : JASN. 2014;25(3):564-572.

Coates TD. Physiology and pathophysiology of iron in hemoglobin-associated diseases. Free radical biology \& medicine. 2014;72:23-40.

Callaghan AL, Moy RJ, Booth IW, Debelle G, Shaw NJ. Incidence of symptomatic vitamin D deficiency. Arch Dis Child 2006;91:606-7.

DeLuca HF. Overview of general physiologic features and functions of vitamin D. Am J ClinNutr 2004;80(6 Suppl):1689S-96S.

Gordon CM, Feldman HA, Sinclair L, Williams AL, Kleinman PK, Perez-Rossello J, et al. Prevalence of vitamin D deficiency among healthy infants and toddlers. Arch PediatrAdolesc Med 2008;162:505-12.

G R, Gupta A. Fortification of foods with vitamin D in India. Nutrients. 2014;6(9):3601-3623.

Golbahar J, Altayab D, Carreon E, Darwish A. Association of vitamin D deficiency and hyperparathyroidism with anemia: a cross-sectional study. Journal of blood medicine. 2013;4:123-128.

Grindulis H, Scott PH, Belton NR, Wharton BA. Combined deficiency of iron and vitamin D in Asian toddlers.Archives of disease in childhood. 1986;61(9):843-848.

Georgina Toussaint-Martinez decastro, Miguel Angel Guagnelli,Patrica Clark, Lucia MendezSanchez, Desiree Lopez-Gonzalez, Juan- Francisco, Gulan-Herrera and Sanchez-Ruiz. Vitamin D, not iron, is the main nutrient deficiency in preschool and school-aged children in Mexico City: A cross-sectional study. Nurt Hosp. 2016; 33(4): 794-800

Halterman JS, Kaczorowski JM, Aligne CA, Auinger P, Szilagyi PG. Iron deficiency and cognitive achievement among school-aged children and adolescents in the United States. Pediatrics. 2001; 107(6):1381-1386.

Iyer P, Diamond F. Detecting disorders of vitamin D deficiency in children: an update. Advances in pediatrics.2013;60(1):89-106.Jin HJ, Lee JH, Kim MK. The prevalence of vitamin D 
deficiency in iron-deficient and normal children under the age of 24 months.Blood research. 2013;48(1):40 -45.

Liang L, Chantry C, Styne DM, Stephensen CB. Prevalence and risk factors for vitamin D deficiency among healthy infants and young children in Sacramento, California.Eur J Pediatr 2010;169:1337-44.

Lee JM, Smith JR, Philipp BL, Chen TC, Mathieu J, Holick MF.Vitamin D deficiency in a healthy group of mothers and newborn infants.ClinPediatr (Phila) 2007;46:42-4.

Lutter CK. Iron deficiency in young children in lowincome countries and new approaches for its prevention. J Nutr. 2008; 138(12): 2523-2528.

Maguire JL, Lebovic G, Kandasamy S, Khovratovich M, Mamdani M, Birken CS, et al. The relationship between cow's milk and stores of vitamin $\mathrm{D}$ and iron in early childhood. Pediatrics. 2013;131(1):e144-e151.

Soliman AT, Eldabbagh M, Elawwa A, Ashour R, Saleem W. The effect of vitamin D therapy on hematological indices in children with vitamin $\mathrm{D}$ deficiency. Journal of tropical pediatrics. 2012;58(6):523-524.

Strand MA, Perry J, Jin M, Tracer DP, Fischer PR, Zhang P, et al. Diagnosis of rickets and reassessment of prevalence among rural children in northern China. PediatrInt 2007;49:202-9.

Uriu-Adams JY, Obican SG, Keen CL. Vitamin D and maternal and child health: overview and implications for dietary requirements. Birth defects research. Part C, Embryo today : reviews. 2013;99(1):24 -44.

Stoltzfus RJ. Iron deficiency: global prevalence and consequences. Food Nutr Bull. 2003; 24(4): 99-103.

Toxqui L, Pérez-Granados AM, Blanco-Rojo R, Wright I, González-Vizcayno C, Vaquero MP. Effects of an Iron or Iron and vitamin D-fortified flavored skim milk on Iron metabolism: A randomized controlled doubleblind trial in Iron-deficient women. Journal of the American College of Nutrition. 2013;32(5):312-320.

Sooragonda B, Bhadada SK, Shah VN, Malhotra P, Ahluwalia J, Sachdeva N. Effect of vitamin $\mathrm{D}$ replacement on hemoglobin concentration in subjects withconcurrent iron-deficiency anemia and vitamin D deficiency: a randomized, single-blinded, placebo-controlled trial. Actahaematologica. 2015;133(1):31-35.

Wagner CL, Taylor SN, Dawodu A, Johnson DD, Hollis BW. Vitamin D and its role during pregnancy in attaining optimal health of mother and fetus. Nutrients. 2012;4(3):208-230.

Yadav D, Chandra J. Iron deficiency: beyond anemia. Indian J Pediatr. 2011; 78(1): 65-72.

Sharma S, Jain R, Dabla PK. The role of 25-Hydroxy vitamin D deficiency in iron deficient children of North India. Indian journal of clinical biochemistry : IJCB. 2015;30(3):313-317.

Yoon JW, Kim SW, Yoo EG, Kim MK. Prevalence and risk factors for vitamin D deficiency in children with iron deficiency anemia. Korean journal of pediatrics. 2012;55(6):206 -211.

Yu Sun Kang, Joon Hwan Kim, EunHeeAhn, Eun-GyongYoo, Moon Kyu Kim. Iron and vitamin D status in breastfed infants and their mothers.Korean Peadiatric Society. 2015; 58(8): 283287

Zhang R, Naughton DP. Vitamin D in health and disease: current perspectives. Nutrition journal. 2010;9(1):65-77. 